\title{
Analysis of Remineralization Potential of Three Different Remineralizing Pastes on Demineralized Enamel: A Comparative Study
}

\author{
Arti Dixit ${ }^{1}$, Mathew O Mampilly², Raghuveer Nallamothu ${ }^{3}$, Rethi Gopakumar $^{4}$, Mahesh Jayachandran $^{5}$, Nithu M Terence $^{6}$
}

\begin{abstract}
Aim: Aim of this research was to evaluate the remineralizing potential of three different remineralizing pastes on enamel that has been demineralized.

Materials and methods: Sixty healthy mandibular single-rooted human premolars extracted for orthodontic reasons from subjects between 18 and 25 years of age were included in this research. An area of $4 \mathrm{~mm} \times 4 \mathrm{~mm}$ (window) was marked on the buccal surfaces of teeth samples, coated with nail varnish except for the window, which was scrutinized for changes in the values subsequent to demineralization as well as remineralization. Samples were kept in demineralizing solution for 96 hours to produce the artificial lesion in the enamel. Consequent to this process of demineralization, the 60 premolar teeth were randomly allocated to the following three groups (20 in each group) depending on the remineralizing paste used for application as group I: bioactive glass constituting remineralizing paste; group II: tricalcium phosphate (TCP) comprising remineralizing paste; and group III: calcium sucrose phosphate (CaSP) remineralizing paste. Following the $\mathrm{pH}$-cycling process, the confocal laser scanning microscope was used to assess the area of demineralization and remineralization.

Results: The mean areas of demineralization were slightly more $(133.24 \pm 0.09)$ in the remineralization paste comprising bioactive glass seconded by the remineralization paste having CaSP $(131.39 \pm 0.18)$, and lastly the remineralizing paste constituting TCP (129.59 \pm 0.14$)$. Maximum areas of remineralization were found in the pastes that had CaSP group $(96.14 \pm 0.04)$, next by the paste having bioactive glass group $(102.18 \pm 0.17)$, and then the remineralization paste constituting TCP $(118.37 \pm 0.21)$. The difference was statistically significant among the three remineralization pastes used.

Conclusion: Amid the confines of this in vitro research, a conclusion that the remineralization pastes comprising CaSP exhibited enhanced remineralization capacity in comparison to the group having bioactive glass and TCP was established.

Clinical significance: Caries is a highly prevalent multifactorial disease, but its progression can be prevented in the initial stage of demineralization through remineralization. Significantly increasing attention to the treatment of carious lesions that are not cavitated by employing noninvasive remineralization methods to achieve restoration of enamel has been rendered in the field of research.

Keywords: Demineralization, Dental caries, pH cycling, Remineralization.

The Journal of Contemporary Dental Practice (2021): 10.5005/jp-journals-10024-3095
\end{abstract}

\section{INTRODUCTION}

Focal disintegration and annihilation of the mineralized tissues of teeth are resulting from the process of dental caries, which is an infectious bacterial pathosis affecting teeth. Dental caries is a community health issue that is prevalent all over the world and affects various communities in the urban and rural areas. Dental caries forms as a result of the cycles of remineralization as well as demineralization with the intervening phases being reversible or nonreversible. One among the most initial presentation of the progress of dental caries is the formation of white spot lesions (WSLs) or areas of demineralization, which are reversible.'

The microbial flora in dental plaque produces acids that dissolve the inorganic portion of enamel by the chemical course of demineralization. The bacteria in this dental plaque generate organic acids that are feeble and reduce the $\mathrm{pH}$ of the surface. These weak acids then undergo diffusion from the plaque within the tooth. As a result, phosphorus and calcium seep out of the enamel by the process of demineralization and reduce the $\mathrm{pH}$ of the plaque consequently to 4.0 to $4.5 .^{2}$

Countless phases of demineralization followed by remineralization affect the enamel surface during its life span. This regulates the progress or reversibility of dental caries.
${ }^{1}$ Department of Public Health Dentistry, Vaidik Dental College and Research Centre, Daman, Daman and Diu, India

${ }^{2}$ Department of Oral and maxillofacial surgery and Dentistry, ESIC Medical College and PG Institute, Bengaluru, Karnataka, India

${ }^{3}$ Division of Orthodontics, Batterjee Medical College, Jeddah, Saudi Arabia

${ }^{4}$ Department of Conservative Dentistry and Endodontics, Noorul Islam College of Dental Sciences, Trivandrum, Kerala, India

${ }^{5}$ Department of Periodontics, Noorul Islam College of Dental Sciences, Trivandrum, Kerala, India

${ }^{6}$ Department of Conservative Dentistry and Endodontics, PMS Dental College, Trivandrum, Kerala, India

Corresponding Author: Arti Dixit, Department of Public Health Dentistry, Vaidik Dental College and Research Centre, Daman, Daman and Diu, India, Phone: +91 9712042464, email: dr.dixitarti@gmail.com

How to cite this article: Dixit A, Mampilly MO, Nallamothu R, et al. Analysis of Remineralization Potential of Three Different Remineralizing Pastes on Demineralized Enamel: A Comparative Study. J Contemp Dent Pract 2021;22(8):939-942.

Source of support: Nil

Conflict of interest: None

@The Author(s). 2021 Open Access This article is distributed under the terms of the Creative Commons Attribution 4.0 International License (https://creativecommons. org/licenses/by-nc/4.0/), which permits unrestricted use, distribution, and non-commercial reproduction in any medium, provided you give appropriate credit to the original author(s) and the source, provide a link to the Creative Commons license, and indicate if changes were made. The Creative Commons Public Domain Dedication waiver (http://creativecommons.org/publicdomain/zero/1.0/) applies to the data made available in this article, unless otherwise stated. 
Multiple agents that cause remineralization have been formulated in the recent times, and the majority of these contain fluoride, phosphate as well as calcium ions in different types and percentages. The aim of these remineralizing agents when applied onto the surface of the tooth is to control the cycles of demineralization and remineralization as dictated by the microenvironment surrounding the tooth. ${ }^{3}$

Bioactive glass may be grinded very well, resulting in median particle size of less than $20 \mu$. This then procures the capability of acting as a biomimetic-mineralizing agent that matches the character of natural mineralization within the body, besides modifying cellular signals in a manner beneficial to the restitution of tissue constitution and functionality. ${ }^{4}$

The ball milling of beta-tricalcium phosphate in its solid-state as well as sodium lauryl sulfate (SLS) results in the production of an additional calcium phosphate complex known as tricalcium phosphate (TCP). TCP thwarts calcium from early interplay with fluoride ions with the resultant formation of calcium fluoride, consequently carrying extra ionic fluoride and calcium to the surface of the enamel. ${ }^{5}$

Soluble forms of calcium and phosphate may be supplied by a calcium orthophosphate complex, which is a nonhygroscopic and finely powdered white substance that tastes neutral blend. It comprises $11.5 \%$ of calcium by dry weight. This complex helps to reduce the acid solubility of enamel and increase the rate of remineralization by a common ion effect. Additionally, it is also known to cause the inhibition of the development and attachment of dental plaque to the tooth surface. ${ }^{6}$ A literature search did not reveal any prior studies comparatively evaluating the effectiveness of the abovementioned remineralizing agents. Thus, this research was performed to evaluate the remineralizing potential of three different remineralizing pastes on enamel that has been demineralized.

\section{Materials and Methods Preparation of Samples}

The present in vitro study was performed in the department of public health dentistry, Vaidik dental college and research center, Daman, India. Sixty healthy mandibular single-rooted human premolars extracted for orthodontic reasons from the subjects between 18 and 25 years of age were included in this research. Following this, the premolars were subjected to disinfection employing $1 \%$ thymol solution and then soaked in it for storage. The buccal surfaces of all teeth were polished, and all teeth were sectioned $1 \mathrm{~mm}$ below the cementoenamel junction. The premolars were mounted in the acrylic blocks only to expose their coronal surface. An area of $4 \mathrm{~mm} \times 4 \mathrm{~mm}$ (window) was marked on the buccal surfaces of teeth samples, coated with nail varnish except for the window, which was analyzed for the change in values following demineralization and remineralization.

\section{Demineralization Procedure}

A mixture of analytical state chemical substances was used to prepare a mock demineralization solution. The constituents of this solution included potassium dihydrogen phosphate $\left(\mathrm{KH}_{2} \mathrm{PO}_{4} \cdot 7 \mathrm{H}_{2} \mathrm{O}\right) 2.2 \mathrm{mmol} / \mathrm{L}$, lactic acid $0.05 \mathrm{mmol} / \mathrm{L}$, and calcium chloride $\left(\mathrm{CaCl}_{2} \cdot 2 \mathrm{H}_{2} \mathrm{O}\right) 2.2 \mathrm{mmol} / \mathrm{L}$. $^{7}$ The acetic acid buffer was added to adjust the ultimate $\mathrm{pH}$ of 4.5. Samples were kept in the demineralizing solution for 96 hours to produce the artificial lesion in the enamel.

Consequent to this process of demineralization, the 60 premolar teeth were allocated at random into one of the following three groups (20 in each group) depending on the remineralizing paste used for application:

- Group I: Bioactive glass constituting remineralizing paste (SHY-NM ${ }^{\circledast}$, Group Pharmaceuticals Ltd., Mumbai, India)

- Group II: TCP comprising remineralizing paste (Clinpro Tooth Creme, 3M ESPE, Saint Paul, Minnesota, United States)

- Group III: Calcium sucrose phosphate (CaSP) remineralizing paste (Toothmin ${ }^{T M}$ paste, Abbott Healthcare, Mumbai, India).

\section{The pH-cycling Procedure}

Following demineralization, all the samples were subjected to rinsing with distilled water for 60 seconds following which they were kept in the $50 \mathrm{~mL}$ artificial saliva solution. The artificial saliva was formulated with the subsequent substances in specific proportions-potassium dihydrogen phosphate $\left(\mathrm{KH}_{2} \mathrm{PO}_{4}\right)$ $0.9 \mathrm{mmol} / \mathrm{L}$, potassium chloride $(\mathrm{KCl}) 50 \mathrm{mmol} / \mathrm{L}$, calcium chloride $\left(\mathrm{CaCl}_{2}\right) 1.5 \mathrm{mmol} / \mathrm{L}$, and tris buffer $20 \mathrm{mmol} / \mathrm{L}{ }^{7}$ These sample teeth were then subjected to treatment with the respective remineralizing paste twice daily for 14 days for 3 minutes utilizing a cotton application tip. Samples were then washed with distilled water and stored for the remaining time in the artificial saliva.

\section{Evaluation of the Remineralization Potential}

The mean area of remineralization was evaluated with the confocal laser scanning microscope (CLSM). The sample teeth in each of the above three groups were subjected to storage in rhodamine $B$ dye $(1 \mathrm{mM})$ for 24 hours. They then underwent slicing and visualization beneath the confocal microscope.

The stained sections were subjected to fixing and mounted onto the microscopic glass slide employing modeling wax. Employing a $10 \times$ intention, the argon laser at a power of $50 \%$ was created by means of a 488-nm excitation wavelength. Confocal slits were set up at $25 \mu \mathrm{m}$ employing a $515-\mathrm{nm}$ long-pass filter. Those regions that were plano-parallel to the samples cut surface were subjected to scanning.

The sound enamel (untreated specimen) appeared pitch black near zero fluorescence (grayscale value approximately 0 ) registers. The induced lesional areas in the demineralized samples exhibited approximate autofluorescence. However, due to the absorption of the rhodamine dye $(0.1 \mathrm{mM})$, the porous layer of demineralization appeared with considerable contrast (higher gray values). Samples that had undergone remineralization exhibited decreased fluorescence (smaller gray values that indicate decreased porosity as well as diffusion of dye or extra mineral). The reduction in the fluorescence (gray values) was related among the three groups to evaluate the remineralization potential of each paste.

\section{Statistical Analysis}

IBM SPSS Statistics for Windows Software, version 22 (IBM Corp., Armonk, New York, United States) was used to analyze the data statistically. Descriptive statistics was employed to compute the mean and standard deviation. The ANOVA and Tukey's post hoc tests were utilized for assessing the comparative effectiveness of various remineralizing pastes. The significance level was established at $5 \%$. 


\section{Results}

Table 1 delineates the portion of mean demineralization among the three study groups. This area of demineralization was slightly more $(133.24 \pm 0.09)$ in the remineralization paste comprising bioactive glass seconded by remineralization paste having CaSP $(131.39 \pm 0.18)$, and lastly the remineralizing paste constituting TCP (129.59 \pm 0.14$)$. No significant difference as analyzed statistically was noted amid the three groups.

Table 2 depicts the mean areas of remineralization as distributed among the three experimental groups. Maximum areas of remineralization were found in the pastes that had CaSP group $(96.14 \pm 0.04)$, next by the paste having bioactive glass group $(102.18 \pm 0.17)$, and then the remineralization paste constituting TCP (118.37 \pm 0.21$)$. The difference was statistically significant among the three remineralization pastes used.

The overall comparative evaluation of the mean remineralization paste groups is depicted in Table 3. The differences between all the groups, except amid group I and group III were statistically significant.

\section{Discussion}

Clinically the earliest detectable sign of dental caries is the incipient enamel lesion or WSL, which becomes detectable radiographically only as the lesion progresses into the enamel and dentin. Owing to the subsurface enamel loss, this lesion looks opaque with a resultant absence of translucency of enamel. Prior to the formation of a cavity,

Table 1: Distribution of mean demineralized areas among three study groups

\begin{tabular}{llll}
\hline Remineralizing paste groups & Mean $\pm S D$ & Fvalue & pvalue \\
\hline $\begin{array}{l}\text { Group I: Bioactive glass } \\
\text { constituting remineralizing paste }\end{array}$ & $133.24 \pm 0.09$ & & \\
$\begin{array}{l}\text { Group II: Tricalcium phosphate } \\
\text { comprising remineralizing paste }\end{array}$ & $129.59 \pm 0.14$ & 21.214 & 0.946 \\
$\begin{array}{l}\text { Group III: Calcium sucrose } \\
\text { phosphate remineralizing paste }\end{array}$ & $131.39 \pm 0.18$ & & \\
\hline
\end{tabular}

Table 2: Distribution of mean remineralized areas among three study groups

\begin{tabular}{llll}
\hline Remineralizing paste groups & Mean $\pm S D$ & Fvalue & pvalue \\
\hline $\begin{array}{l}\text { Group I: Bioactive glass } \\
\text { constituting remineralizing paste }\end{array}$ & $102.18 \pm 0.17$ & & \\
$\begin{array}{l}\text { Group II: Tricalcium phosphate } \\
\text { comprising remineralizing paste }\end{array}$ & $118.37 \pm 0.21$ & 22.416 & 0.001 \\
$\begin{array}{l}\text { Group III: Calcium sucrose } \\
\text { phosphate remineralizing paste }\end{array}$ & $96.14 \pm 0.04$ & & \\
\hline
\end{tabular}

Table 3: Overall comparisons of mean remineralization pastes using Tukey HSD

\begin{tabular}{lccc}
\hline Group & Compared with & Mean difference (I-J) & Sig. \\
\hline \multirow{2}{*}{ Group I } & Group II & -16.19 & 0.001 \\
& Group III & 6.04 & 0.091 \\
\multirow{2}{*}{ Group II } & Group I & 16.19 & 0.001 \\
& Group III & 22.23 & 0.001 \\
\multirow{2}{*}{ Group III } & Group I & -6.04 & 0.091 \\
& Group II & -22.23 & 0.001 \\
\hline
\end{tabular}

at this point, preventive methods may be instituted to cease or undo the progress of the lesion. When the lesion is not treated, it eventually results in a cavity due to dental caries. Initial lesions can be identified with the latest dental caries detecting devices that can diagnose minute lesions for the institution of remineralization with preventive methods. Applying strategies to control, arrest, or reverse the disease process can reduce the economic burden, pain, and suffering of placing and replacing restorations. ${ }^{8}$

In the current research, $\mathrm{pH}$-cycling execution was done for 14 days to permit ample time to create alterations in the demineralized enamel sample. The model here allowed exposure of the enamel surfaces to 96 hours of demineralization employing the acetic acid buffer with a $4.5 \mathrm{pH}$. This procedure is similar to that followed by Featherstone ${ }^{9}$ and Ten Cate et al. ${ }^{10}$ for $\mathrm{pH}$ cycling to assess the dental caries preventing materials action on the cycles of demineralization as well as remineralization of enamel.

In this research, greater mean remineralizing regions were noted in the CaSP constituting remineralization paste group, next by the one consisting of bioactive glass, and last by the TCP constituting paste. The remineralization paste containing TCP (Clinpro Tooth Crème) is a $0.21 \% \mathrm{w} / \mathrm{w}$ sodium fluoride antidental caries paste having $950 \mathrm{ppm}$ of fluoride as well as a functionalized (f)-TCP constituent. Two percentage SLS component of f-TCP avoids the reaction of chemical phosphate and fluoride. The functionality of the TCP is determined by the organic covering of SLS on TCP, which thwarts unwanted action with fluoride. This organic portion consequently undergoes dissolution in saliva, leaving the particles in their active form. These results differ from the research by Karlinsey et al. ${ }^{11}$ who reported differences that were statistically significant amid other groups wherein the 500ppm fluoridecontaining dentifrices aided inappreciably low remineralization as related to the $1150 \mathrm{ppm}$ fluoride and 500 ppm fluoride-plus-f-TCP dentifrices.

Different qualitative and quantitative methods that measure changes in tooth mineral content, such as transverse microradiography, CLSM, polarization-sensitive optical coherence tomography, light scattering, energy dispersive X-ray analysis, polarized light microscopy as well as cross-sectional microhardness estimation are being utilized to assess the remineralization capacity of the number of commercial remineralization products. A vital imaging technique is the CLSM technique that depends on the optical presentation of light within the samples. Although detecting emission with confocal analysis is a possibility with confocal scan, it can also cause excitation like fluorescence. Such optical features are beneficial in recognizing caries as well as noncarious areas on the tooth. ${ }^{12}$

The CaSP paste group in this research exhibited enhanced remineralizing capacity when compared to the other two groups. There were no statistically significant differences pertaining to the remineralizing ability amid the groups using CaSP and bioactive glass. This could be due to CaSP provides both calcium and phosphate ions in a soluble form in high concentrations This combination has a high water solubility index, which releases more free calcium and phosphate ions as compared to saliva. It reduces the rate of demineralization of enamel, increases the rate of remineralization by a common ion effect, and actively neutralizes the plaque acids. This is the main advantage of CaSP remineralization paste. Similarly, Menon et al. ${ }^{13}$ and Gangrade et al. ${ }^{14}$ concluded that CaSP enhances the calcium quantity in saliva, leading to a higher level of calcium being deposited on the 
tooth surface that not just improves calcium depositing on tooth surface but additionally causes a reduction in plaque depositing on the teeth.

The remineralizing capacity of CaSP was estimated by Kaur et al. $^{15}$ The study came to a conclusion that the remineralization efficiency of CaSP did not differ significantly from various other pastes though CaSP depicted marginally greater remineralizing capacity that is in agreement with the current research.

In a bioactive glass, the glass material dissolves into an aqueous solution, followed by a $\mathrm{pH}$ rise. The $\mathrm{pH}$ rise promotes the precipitation of hydroxyapatite, the main component of mineralized enamel and dentine. Calcium and phosphate ions from the bioactive glass and mineralizing agents in saliva may enhance the process of mineralization. ${ }^{16}$ In the present study, the maximum remineralized areas were found in the remineralizing paste containing bioactive glass group than the remineralizing paste containing TCP group. An enhanced postremineralizing value was found in the research by Vahid Golpayegani et al., ${ }^{17}$ in which bioactive glass containing paste seemed to have a better effect on the caries-like regions.

A limitation of this study is that the lesions created in the study to replicate the demineralized surfaces might not represent WSLs completely. The in-vitro remineralizing process may differ in contrast to the dynamics of the intricate physiological systems that are there in vivo, such as within the mouth. Hence, a direct application of these results to clinical situations must be implemented cautiously.

\section{Conclusion}

Amid the confines of this in vitro research, a conclusion that the remineralization pastes comprising CaSP exhibited enhanced remineralization capacity in comparison to the group having bioactive glass and TCP was established.

\section{References}

1. Vashisht R, Indira R, Ramachandran S, et al. Role of casein phosphopeptide amorphous calcium phosphate in remineralization of white spot lesions and inhibition of Streptococcus mutans. J Conserv Dent 2013;16(4):342-346. DOI: 10.4103/0972-0707.114370.

2. Chandru TP, Yahiya MB, Peedikayil FC, et al. Comparative evaluation of three different toothpastes on remineralization potential of initial enamel lesions: A scanning electron microscopic study. Indian J Dent Res 2020;31(2):217-223. DOI: 10.4103/ijdr.IJDR_745_18.

3. Rao A, Malhotra N. The role of remineralizing agents in dentistry: a review. Compend Contin Educ Dent 2011;32(6):26-33. Available from: https://pubmed.ncbi.nlm.nih.gov/21894873/.
4. Burwell AK, Litkowski LJ, Greenspan DC. Calcium sodium phosphosilicate (NovaMin): remineralization potential. Adv Dent Res 2009;21(1):35-39. DOI: 10.1177/0895937409335621.

5. Karlinsey RL, Pfarrer AM. Fluoride plus functionalized $\beta$-TCP: a promising combination for robust remineralization. Adv Dent Res 2012;24(2):48-52. DOI: 10.1177/0022034512449463.

6. Raksha B, Mithra H. An overview on remineralizing agents. Indian J. Appl Res 2015;6(1):331-336. Available from: https://www.worldwide journals.com/indian-journal-of-applied-research(IJAR)/fileview/ January_2016_1451542453__100.pdf.

7. Joshi C, Gohil U, Parekh V, et al. Comparative evaluation of the remineralizing potential of commercially available agents on artificially demineralized human enamel: an in vitro study. Contemp Clin Dent 2019;10(4):605-613. DOI: 10.4103/ccd.ccd_679_18.

8. Rajendran R, Kunjusankaran RN, Sandhya R, et al. Comparative evaluation of remineralizing potential of a paste containing bioactive glass and a topical cream containing casein phosphopeptideamorphous calcium phosphate: an in vitro study. Pesquisa Brasileira em Odontopediatria e Clínica Integrada 2019;19(1):e4668. DOI:10.4034/PBOCI.2019.191.61.

9. Featherstone JD. Modeling the caries-inhibitory effects of dental materials. Dent Mater 1996;12(3):194-197. DOI: 10.1016/s01095641(96)80021-2.

10. Ten Cate JM, Buijs MJ, Miller CC, et al. Elevated fluoride products enhance remineralization of advanced enamel lesions. J Dent Res 2008;87(10):943-947. DOI: 10.1177/154405910808701019.

11. Karlinsey RL, Mackey AC, Walker TJ, et al. In vitro remineralization of human and bovine white-spot enamel lesions by NaF dentifrices: a pilot study. J Dent Oral Hyg 2011;3(2):22-29. Available from: https:// pubmed.ncbi.nlm.nih.gov/21643437/.

12. Kishen A, Shrestha A, Rafique A. Fiber optic backscatter spectroscopic sensor to monitor enamel demineralization and remineralization in vitro. J Conserv Dent 2008;11(2):63-70. DOI: 10.4103/0972-0707.44053.

13. Menon LU, Varma RB, Kumaran P, et al. Efficacy of a calcium sucrose phosphate based toothpaste in elevating the level of calcium, phosphate ions in saliva and reducing plaque: a clinical trial. Contemp Clin Dent 2018;9(2):151-157. DOI: 10.4103/ccd.ccd_562_17.

14. Gangrade A, Gade V, Patil S, et al. In vitro evaluation of remineralization efficacy of different calcium- and fluoride-based delivery systems on artificially demineralized enamel surface. J Conserv Dent 2016;19(4):328-331. DOI: 10.4103/0972-0707.186449.

15. Kaur G, Sanap AU, Aggarwal SD, et al. Comparative evaluation of two different remineralizing agents on the microhardness of bleached enamel surface: results of an in vitro study. Indian J Dent Res 2015;26(2):176-179. DOI: 10.4103/0970-9290.159154.

16. Jones JR. Review of bioactive glass: from Hench to hybrids. Acta Biomater 2013;9(1):4457-4486. DOI: 10.1016/j.actbio.2012.08.023.

17. Vahid Golpayegani M, Sohrabi A, Biria M, et al. Remineralization effect of topical NovaMin versus sodium fluoride (1.1\%) on caries-like lesions in permanent teeth. J Dent (Tehran) 2012;9(1):68-75. Available from: https://pubmed.ncbi.nlm.nih.gov/22924104/. 